\title{
Intersetorialidade ou diálogos setoriais? Reflexões a partir da experiência do Projeto Teias-Escola Manguinhos, Rio de Janeiro
}

\author{
Intersectoriality or sectorial dialogues? Reflections based on the \\ experience of the Projeto Teias-Escola Manguinhos, Rio de Janeiro
}

\author{
Antonio Lima Ornelas', Maria Gracinda Carvalho Teixeira²
}

\begin{abstract}
RESUMO O estudo das políticas públicas pode ser compreendido como um campo interdisciplinar, o que chama a atenção para o seu diálogo setorial. Nesse sentido, a saúde apresenta-se como uma temática ampla capaz de unificar os demais setores. O Projeto Teias surge no território de Manguinhos como proposta de política pública intersetorial, em que pese as discordâncias referentes à sua formulação. O objetivo deste artigo é contribuir com o debate contemporâneo acerca da intersetorialidade, explorando principalmente suas fragilidades e conflitos, a fim de situá-la dentro de um possível novo referencial teórico-empírico, partindo da experiência do Projeto Teias-Escola Manguinhos.
\end{abstract}

PALAVRAS-CHAVE Políticas públicas; Saúde; Ação intersetorial.

ABSTRACT The study of public policies can be construed as an interdisciplinary domain, which brings the focus of attention to its sectorial dialogue. In this sense, the health area provides ample theme material, and is capable of unifying the other areas. The Projeto Teias is born in the borough of Manguinhos as a proposal for an intersectorial public policy, despite the disagreements regarding its formulation. The goal of this article is to contribute to the contemporary debate of the intersectoriality, exploring mainly its frailties and dilemmas, in order to place it within a possible and new theoretical-empirical reference, based on the experience in the Projeto TeiasEscola Manguinhos.

KEYWORDS Public policies; Health; Intersectoral action.

1 Fundação Oswaldo Cruz (Fiocruz), Diretoria de Planejamento Estratégico (Diplan) - Rio de Janeiro (RJ), Brasil.

ornelas@fiocruz.br

2 Universidade Federal Rural do Rio de Janeiro (UFRRJ), Programa

de Pós Graduação em Administração (PPGA), Rio de Janeiro (RJ), Brasil. gracinda@uol.com.br 
10 nome 'Projeto Teias' foi adotado sem levar em consideração a definição convencional de projeto, cuja característica principal aponta para um conjunto de ações com início, meio e fim. Sua concepção não se coaduna com tal pressuposto, tendo em vista que foi elaborado sem que fosse imposto um prazo para a sua finalização.

\section{Introdução}

De maneira geral, o estudo das políticas públicas pode ser compreendido como um campo interdisciplinar articulado, o que chama a atenção para o seu diálogo setorial. Partindo da definição apresentada por Marques (2000), entende-se setor como o agrupamento isolado de papéis sociais, funcionando de forma vertical e autônoma, submetidos à tentativa de regulação do Estado. O setor pode estar associado a uma determinada circunscrição espacial ou a um domínio de atividade, como, por exemplo, segurança, indústria ou, no que mais interessa aqui, saúde.

De acordo com Almeida Filho (2000), a saúde apresenta-se como uma temática ampla capaz de unificar todas as demais, tornando-se, na prática, a conciliadora de um conjunto de saberes que relaciona cuidados, carências, necessidades e fatores sociais com as responsabilidades de entes estatais e privados.

O Projeto Teias (Território Integrado de Atenção à Saúde) ${ }^{1}$ une a Fundação Oswaldo Cruz (Fiocruz), o Governo do Estado e a Secretaria Municipal de Saúde do Rio de Janeiro, a fim de promover o acesso da população moradora do Complexo de Manguinhos, Zona Norte da cidade do Rio de Janeiro, às ações e aos serviços de saúde. Manguinhos revela-se como um espaço social heterogêneo, territorialmente vulnerável, caracterizado pela incerteza no provimento de serviços públicos essenciais, pela provisoriedade das moradias e os conflitos vinculados ao comércio ilegal de drogas (FERNANDES; COSTA, 2009).

A intersetorialidade, da forma como é compreendida em termos práticos, tem-se reduzido a uma "estratégia de interferência em problemáticas complexas" (ALMEIDA FILHO, 2000, P. 31) e, por que não dizer, contemporâneas, de certa forma coibindo a ampliação da discussão acerca de abordagens mais adequadas para a elaboração de políticas públicas focadas em uma maior articulação, em território marcados por vulnerabilidades sociais.

Assim, o objetivo deste artigo é contribuir com o debate contemporâneo acerca da intersetorialidade, explorando principalmente suas fragilidades e conflitos, a fim de situá-la dentro de um possível novo referencial teórico-empírico, partindo da experiência prática do Projeto Teias-Escola Manguinhos.

Explicam Noronha, Machado e Lima (2011) que o marco da Reforma Sanitária no Brasil foi a VIII Conferência Nacional de Saúde, realizada em 1986. O efeito do intenso debate a que se seguiram os dois anos posteriores resultou na inclusão da seguridade social na nova Constituição Federal, promulgada em 1988. A lei 8.080, conhecida como Lei Orgânica da Saúde, iniciou o processo de regulamentação do funcionamento de um modelo público de ações e serviços de saúde, ordenado pelo que viria a ser conhecido como Sistema Único de Saúde (SUS):

\section{Orientado por um conjunto de princípios e dire- trizes válidos para todo o território nacional, par- te de uma concepção ampla do direito à saúde e do papel do Estado na garantia desse direito, in- corporando, em sua estrutura institucional e de- cisória, espaços e instrumentos para democrati- zação e compartilhamento da gestão do sistema de saúde. (NORONHA; MACHADO; LIMA, 2011, P. 435).}

A regulamentação estrita do SUS deu-se através da formulação de Normas Operacionais Básicas (NOBs). A NOB n. ${ }^{0}$ 96, em particular, estabeleceu a transferência direta de recursos do Fundo Nacional de Saúde (FNS) para os fundos municipais, além de consolidar o Programa Saúde da Família (PSF) como modelo de Atenção Básica à saúde (GERSCHMAN, 2008).

Realizada em 2003, a XII Conferência Nacional de Saúde definiu o PSF como ator central da prática intersetorial (12 CONFERÊNCIA NACIONAL DE SAÚde, 2004). Definido como "um modelo de Atenção Básica à saúde com foco na unidade familiar e construído 
operacionalmente na esfera comunitária" (ANDRADE; BEZERRA; BARRETO, 2005, P. 329), O PSF surgiu formalmente no Brasil como política pública de saúde no ano de 1994. Dez anos depois, contava com mais de 20 mil equipes cobrindo cerca de $90 \%$ dos municípios brasileiros, o que equivale a mais de 70 milhões de pessoas (ANDRADE; BEZERRA; BARRETO, 2005).

Segundo Bodstein (2014), Manguinhos teve sua primeira experiência intersetorial em 1999, através do projeto que ficou conhecido como DLIS (Desenvolvimento Local Integrado e Sustentável). Pautado pela promoção à saúde e pelo desenvolvimento social, o sucesso do projeto dependia também da capacidade de mobilização e participação comunitária (BODSTEIN, 2014). Contudo, de acordo com a autora, já naquele momento era possível identificar dificuldades vinculadas ao diálogo entre setores e a necessidade de investimentos significativos (BODSTEIN, 2014).

Da mesma maneira, estudos importantes, como o de Teixeira e Paim (2000), já enumeravam, as dificuldades de operacionalização de práticas inovadoras que auxiliem a composição de abordagens para políticas públicas articuladas. Conforme os autores, os acordos políticos de coerência ideológica duvidosa, os interesses das elites, o burocratismo, o corporativismo e as limitações econômicas constituem sérios entraves que de forma alguma podem ser desconsiderados no desenho estratégico das intervenções intersetoriais (TEIXEIRA; PAIM, 2000).

Em trabalho recente, Akerman et al. (2014, P. 4292) afirmam que, embora seja um dos assuntos atualmente mais estudados na gestão pública, a intersetorialidade carece de uma agenda de pesquisas que crie condições para sua transformação em "práxis de governo". Nesse sentido, elaboram uma definição operacional de intersetorialidade a partir de um roteiro exploratório guiado por questões do tipo ‘o que', 'como', ‘com quem' e 'para que’:

[...] a intersetorialidade seria definida como um modo de gestão [o que] desenvolvido por meio de processo sistemático de [como] articulação, planejamento e cooperação entre os distintos [com quem] setores da sociedade e entre as diversas políticas públicas para atuar sobre [para que] os determinantes sociais. (AKERMAN ET AL., 2014, P. 4294).

Para além do estritamente operacional, os autores avançam na discussão especulando que a intersetorialidade pode ser melhor compreendida como a conexão de vertentes que articula pressupostos ético-políticos, de enfrentamento de problemas, comunicacionais, relacionais, participativos e integralizantes. Desse raciocínio, deriva a ideia de IntersetorialdeS (sic) como "síntese plural" (AKERMAN ET AL., 2014, P. 4297) de três ondas: a utilitarista e a racional, essas duas ainda vigentes, e a interdependente, que está por vir. Em outras palavras, teorizam que o momento atual caracteriza-se mais por práticas setoriais vinculadas a arranjos diversos do intersetorial, este ainda mantido como possibilidade futura.

Contribuindo para essa noção de que a intersetorialidade é de fato um desafio difícil de ser encarado, Shankardass et al. (2011) fizeram uma revisão bibliográfica sobre o tema, estudando artigos acadêmicos dos últimos 60 anos. Nos mais de 5 mil trabalhos encontrados, menos de $20 \%$ trataram de experiências que, efetivamente, demonstraram-se integrativas.

Andrade (2006, P. 25) procura explicar o problema indicando que os conceitos de promoção à saúde e de intersetorialidade estabelecem uma 'tensão paradigmática', a partir do momento que são confrontados com "aparatos fundados numa lógica setorial e verticalmente hierarquizada" (ANDRADE, 2006, P. 25). Completa o autor que essas ideias, ao mesmo tempo em que reconhecem os determinantes sociais como condicionantes de boa saúde, confiam seu processo de formulação política a uma lógica setorial (ANDRADE, 2006), o que, necessariamente, produz o que o ele chama de "dilema da intersetorialidade" (ANDRADE, 2006, P. 27). Esse dilema configura-se 
na permanente contradição entre experiências intersetoriais isoladas e políticas públicas "hegemonicamente setorializadas" (ANDRADE, 2006, P. 284).

Para Marques (2000), a abordagem estritamente setorial configura-se como uma estratégia estatal para regulamentar, de forma vertical, determinados focos de atividade. De acordo com o autor, um 'setor' pode ser definido como:

[...] o conjunto de papéis sociais estruturados em torno de uma lógica vertical e autônoma de reprodução. A estruturação dos setores segue frequentemente, portanto, uma lógica profissional [dos papéis sociais], agrupando os atores de um dado campo de atividade, suas ideias e suas práticas. [...] Além disso, o quadro da análise setorial enfoca o conjunto agregado de indivíduos, entidades, etc., não destacando de forma central as relações entre eles. (MARQUES, 2000, P. 42-43).

A partir do que escreve o autor, pode-se supor que a formulação de políticas públicas mantém-se vinculada a um caráter setorial, resultando em ações caracterizadas pelo insulamento, pela verticalização e pelo negligenciamento de "importantes processos e dinâmicas passíveis de estudo através da consolidação direta de vínculos e relações" (MARQUES, 2000, P. 33).

Entretanto, existem estudiosos de políticas públicas, como Junqueira (2000), que tendem a escutar com mais nitidez os ecos da interdependência e da integração. $\mathrm{O}$ autor aponta a emergência de enfoques nos quais se privilegiam a integração e a reconstrução das práticas e da cultura das organizações gestoras das políticas sociais, visando impedir que as políticas públicas permaneçam circunscritas ao domínio setorial (JUNQUEIRA, 2000).

Avançando no tema, Almeida Filho (1997) identifica um conjunto de discursos resultantes do cruzamento de campos inicialmente disciplinares que procura eliminar da ciência o insulamento em detrimento da complementaridade. Surge, assim, uma discussão centrada em conceitos, como multidisciplinaridade, pluridisciplinaridade, interdisciplinaridade e transdisciplinaridade, entre outros. Nessa mesma direção, orientam-se também os estudos de Santos (2007).

De acordo com a referida autora, a solução de um dado problema, compreendido a partir de uma perspectiva multidisciplinar, pressupõe a reunião de conhecimentos de diversas áreas sem que haja conexão entre elas. Em um contexto multidisciplinar, as disciplinas não se integram nem se transformam, podendo ser novamente separadas sem perder suas características fundamentais. Em outras palavras, as fronteiras disciplinares permanecem intactas "sem que um novo aparato conceitual seja discutido" (SANTOS, 2007, P. 53).

Ainda conforme Almeida Filho (1997), uma lógica pluridisciplinar ainda implica na justaposição das disciplinas, contudo, agora, com objetivos comuns. Não se verifica diferença hierárquica e existe uma perceptível perspectiva de complementaridade. Poderse-ia dizer que as temáticas de umas completam as temáticas das outras.

Quando duas ou mais disciplinas integram-se em uma mesma investigação promovendo um intercâmbio capaz de gerar mudanças conceituais a partir de novas teorias e metodologias compartilhadas, diz-se que se adotou um ponto de vista interdisciplinar (SANTOS, 2007, P. 54). Nessa perspectiva, as fronteiras disciplinares são frágeis e permeáveis a novas formulações e definições.

Seguindo nas ideias de Almeida Filho (1997), pode-se escrever que a transdisciplinaridade consiste na integração de diferentes disciplinas mediante o compartilhamento fundamental de uma 'axiomática geral'; estrutura-se em um "sistema multiníveis com diferentes objetivos, horizontalizado, coordenado não por uma disciplina, mas por um conjunto de conhecimentos comuns" (ALMEIDA FILHO, 2000, P. 17). 
Ou seja, o grau de integração entre as disciplinas eleva-se a um patamar que praticamente inviabiliza a sua separação. Almeida Filho (2000) ainda acrescenta que, efetivamente, poucos autores propuseram alguma sistematização deste conceito, entre os quais se encontra o francês Edgar Morin.

Para Morin (1996), a tendência à fragmentação e à disjunção resulta no insulamento do conhecimento, afastando-o cada vez mais da prática reflexiva coletiva. Dessa forma, o saber torna-se redutível a dados computados e manipulados, transformando os especialistas em verdadeiros ignorantes naquilo que não diz respeito às suas disciplinas (MORIN, 1996). O que Morin (1996) defende, portanto, é uma nova ciência, consciente de que deve preencher lacunas e ignorar fronteiras:

De toda parte surge a necessidade de um princípio de explicação mais rico do que o princípio de simplificação (separação/redução), que podemos denominar princípio de complexidade. É certo que ele se baseia na necessidade de distinguir e de analisar, como o precedente, mas, além disso, procura estabelecer a comunicação entre aquilo que é distinguido: o objeto e o ambiente, a coisa observada e o seu observador. Esforça-se não por sacrificar o todo à parte, a parte ao todo, mas por conceber a difícil problemática da organização. (MORIN, 1996, P. 30).

Em outras palavras, trata-se de conceder protagonismo à complexidade na medida em que esta seria responsável por conduzir a ênfase da concepção 'moriniana' na direção do processo permanente de interação entre as partes e o todo, as primeiras assumindo uma dupla identidade - mantendo suas propriedades sem se confundir com o todo - e, concomitantemente, conservando sua "cidadania sistêmica” (MORIN, 1996, P. 260). Logo, o que Morin abomina é a interdependência estática.

Descrever abordagens é uma escolha epistemológica que, fundamentada teoricamente nas características salientadas pela literatura especializada, auxilia a análise de fenômenos sociais complexos e eivados de particularidades, como as políticas públicas. Dessa forma, buscou-se, a seguir, a sistematização do debate empreendido até aqui através da transferência dos conceitos discutidos do campo disciplinar para o âmbito setorial vinculado à formulação de políticas públicas. Inicia-se com a apresentação da figura 1:

Figura 1. Abordagens não setoriais na formulação de políticas públicas

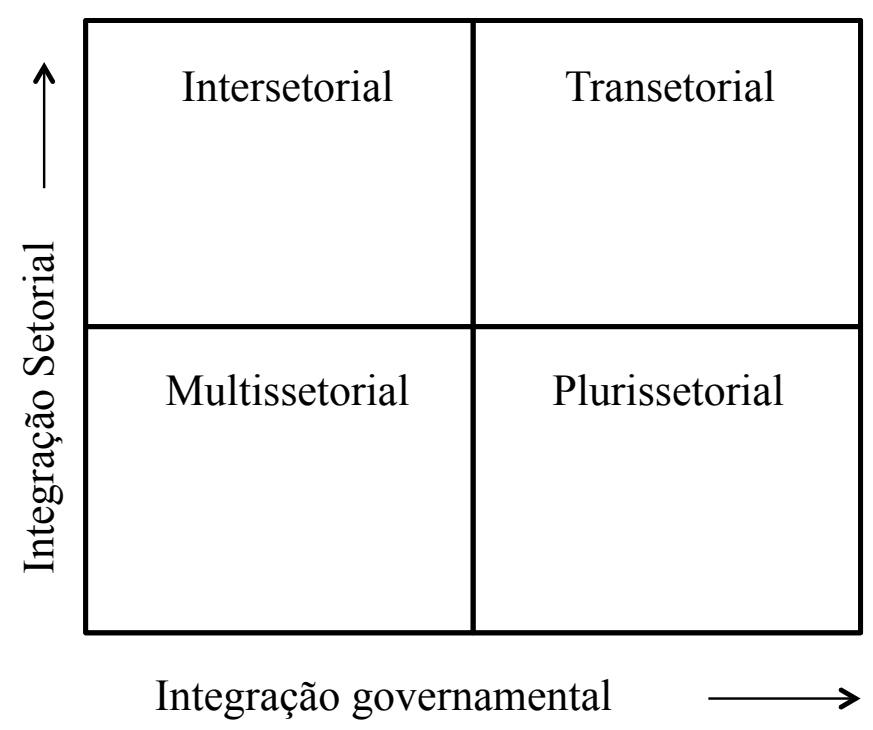

Nota: Elaboração própria 
Este esquema sugere um enfoque teórico para elaboração de políticas públicas que parte de uma perspectiva setorial e avança por dois eixos determinantes. Primeiro, a ampliação da integração governamental, o que, em outras palavras, pode ser compreendida como a redução progressiva da lógica compartimentalizada que afeta não somente a concepção técnica de setor como também o grau de vinculação e entendimento entre as diversas instâncias governamentais (no caso do Brasil, federais, estaduais e municipais). Segundo, o aumento do grau de integração entre esses setores, entendendo que esse pressuposto encaixa-se melhor nos conceitos propostos, em contraste com uma equivocada lógica sistêmica que inibe conflitos e singularidades. Nesse sentido, emergem quatro abordagens admissíveis: a multissetorial, a plurissetorial, a intersetorial e a transetorial.

Assim, de maneira análoga às ideias descritas até aqui, entende-se a multissetorialidade como alternativa para abordagem na formulação de políticas públicas cujo enfoque concebe os setores como fatias disjuntas de um processo estático, que não interagem a ponto de produzir resultados diversos dos que produziriam se fossem estabelecidas de forma puramente isolada.

Políticas públicas concebidas segundo uma abordagem plurissetorial ainda mantêm a desarticulação enfatizada pela multissetorialidade. Contudo, a maior integração governamental provocada pela unificação dos objetivos tende a reduzir a justaposição dos setores e as crises de autonomia, criando ações complementares entre si.

De forma idêntica, o modelo intersetorial de políticas públicas introduz em sua análise a compreensão articulada dos setores. Contudo, conforme explica Almeida Filho (2000), um desses setores deve assumir uma função hierárquica superior, integradora, mediadora e coordenadora, normalmente "determinada por referência à sua proximidade a uma temática unificada" (ALMEIDA FILHO, 2000,
P. 17). Surge como a principal abordagem contemporânea para políticas públicas de saúde que a conectam a determinantes sociais.

Sustentado pelos trabalhos seminais de Morin e pelos escritos contemporâneos de Almeida Filho, entende-se que a transetorialidade apresenta-se como a representação do pensamento complexo no estudo de políticas públicas. A essência de sua concepção assenta-se menos na delimitação de finalidade dos diferentes setores que nas interações ativas que os articula. Em outras palavras, a ênfase da transetorialidade, adaptando o que disse Morin (1996), desloca-se dos setores para os processos de "circularidade construtiva" (MORIN, 1996, P. 259), que se estabelecem entre eles.

\section{Material e método}

$\mathrm{O}$ artigo se dispõe a examinar uma política pública, focalizando o caráter intersetorial de sua elaboração, segundo o qual essa mesma política não pode ser compreendida de forma fragmentada. Entende-se esta análise como de natureza qualitativa, por ser a abordagem mais aderente com seu objeto, especialmente quando deixa claro que se trata de identificar questões problemáticas relacionadas à formulação do Projeto TeiasEscola Manguinhos como política pública intersetorial. A coleta de dados se deu através de pesquisa documental, pesquisa empírica com fontes orais por meio de entrevistas em profundidade com sete sujeitos, além da pesquisa bibliográfica.

Os sete sujeitos de pesquisa foram selecionados segundo o cumprimento de ao menos um dos seguintes critérios, enquanto atores envolvidos com a elaboração do Projeto Teias-Escola Manguinhos: (a) ter participado da formulação técnica do Projeto Teias-Escola Manguinhos; (b) ter participado da articulação política que resultou na implementação do Projeto TeiasEscola Manguinhos; (c) ter ocupado cargo de nível decisório relevante com referência 
às ações adotadas para elaboração do Projeto Teias-Escola Manguinhos e; (d) ser comprovadamente detentor de notório saber na área da saúde pública e coletiva. Excluíramse desses critérios características pessoais, como gênero e idade.

Os dados foram analisados com o uso da técnica de análise de conteúdo. Conforme escreve Vergara (2012), analisar o conteúdo de um dado material consiste na identificação do que este diz sobre um determinado tema. Acrescenta Bardin (1977, P. 42) que a análise de conteúdo pode ser compreendida como "um conjunto de técnicas de análise das comunicações". É um procedimento comumente utilizado na interpretação de transcrições de entrevistas e de material institucional. Em outras palavras, ao auxiliar a sistematização das descrições, a análise de conteúdo contribui para a reinterpretação e compreensão mais aprofundada das mensagens.

\section{Resultados e discussão}

A estratégia de aperfeiçoamento do SUS, proposta pelo Ministério da Saúde, assenta-se sobre um modelo que tem a Atenção Primária à Saúde como porta de entrada principal e ordenadora do acesso aos demais serviços. Em Manguinhos, essa porta de entrada é constituída pela saúde da família, a principal ação do Projeto Teias, estruturada em 13 equipes compostas cada uma por um médico, um enfermeiro, um técnico de enfermagem e seis agentes comunitários de saúde. Cada equipe é responsável por cobrir uma subdivisão do território de Manguinhos, ocupando-se de aproximadamente 3 mil moradores. Conforme registra o documento 'A experiência do Território Escola Manguinhos na Atenção Primária de Saúde' (ENGSTROM; FONSECA; LEIMANN, 2012), são ao todo aproximadamente 200 profissionais envolvidos e duas unidades ambulatoriais: a Clínica da Família Victor Valla e o Centro de Saúde Escola Manguinhos (CSE). Existe uma única porta de entrada para urgências e emergências que é a Unidade de Pronto Atendimento (UPA).

O Núcleo de Apoio à Saúde da Família (Nasf Manguinhos) constitui uma retaguarda especializada de assistência voltada para o suporte técnico-pedagógico às Equipes de Saúde da Família. Dentro do Nasf, surgiu o embrião do Programa de Atenção Domiciliar, que consiste no cuidado diferenciado e por breve período aos idosos com dependência, pacientes acamados, deficientes, jovens vítimas da violência (paraplégicos vítimas de causas externas), entre outros casos, como se verifica no documento mencionado no parágrafo anterior.

Outra iniciativa desse programa é a atenção à saúde da população de rua, batizada com o nome de Consultório na Rua. Em Manguinhos, os moradores de rua encontram-se, em sua grande maioria, envolvidos com o uso abusivo de drogas, principalmente o crack, e o álcool. O Consultório na Rua visa garantir para essa população o acesso à atenção à saúde de forma rápida e eficiente, através da estratégia de redução de danos, estabelecida pelo Ministério da Saúde como mais adequada a este contexto.

A Academia Carioca da Saúde também compõe o portfólio de ações do Projeto Teias. Sua proposta é promover a atividade física no território como forma de prevenção e controle das doenças cardiovasculares e outras condições crônicas. Também tem o objetivo de disseminar a adoção de um estilo de vida mais saudável.

A gestão do Projeto Teias-Escola Manguinhos estabelece-se através de uma parceria regulada por um contrato de gestão celebrado entre a Escola Nacional de Saúde Pública Sergio Arouca (Ensp) e a Secretaria Municipal de Saúde (SMS) por meio da Fundação para o Desenvolvimento Científico e Tecnológico em Saúde (Fiotec) - fundação de apoio vinculada à Fiocruz, convertida juridicamente em Organização Social (OS) para fins de adequação ao modelo de gestão municipal dos serviços de saúde. 
Nesse modelo, diversos profissionais são contratados pelo regime celetista através das OSs, o que acontece também no Projeto Teias.

Na tentativa de dar validade à participação cidadã no âmbito do projeto, a gestão do Teias Escola-Manguinhos trabalha em conjunto com o Conselho Gestor Intersetorial (CGI), com os conselhos internos das clínicas da família, além de possuir o auxílio de apoiadores institucionais. O CGI de Manguinhos é composto por 48 conselheiros, de forma paritária na participação do poder público e da comunidade, incluindo, além da representação do setor saúde, o setor da educação e da assistência social. A intersetorialidade estaria presente também na representação comunitária, por segmentos sociais.

Ao longo dos depoimentos dos entrevistados, nota-se que justamente a criação do CGI é um primeiro fator de grande discordância que, de certa forma, alcança significativa relevância nessa discussão. Enquanto para alguns atores importantes essa iniciativa revela-se como inovadora e bastante efetiva, para outros consiste em um flagrante fracasso, a reboque de falhas estruturais que acompanharam a formulação desde seu início.

O princípio básico da concepção do CGI é promover a integração do maior número possível de atores sociais inseridos no território, a fim de conceder voz a todos os grupos, movimentos e associações, sem distinções e hierarquizações em suas demandas. Uma vez formalmente constituído, o CGI surge no território com a prerrogativa de ser uma instância deliberativa ampla e democrática, na linha do que determinam as diretrizes do SUS:

O ponto forte foi a construção do Colegiado [sic] Gestor Intersetorial. De fato ele é o produto, vamos dizer, mais consistente e um dispositivo muito potente dessa articulação. No nosso comitê [sic] a gente inovou: se a gente está falando de intersetorialidade porque só vai ter assento o segmento saúde? Então nós fizemos o Comitê [sic] Gestor Intersetorial com ampla consulta pública na comunidade, foi um movimento de quase 1 ano de reuniões, mas que foram muito importantes para consolidar isso. (Entrevistado 3).

Contudo, o diagnóstico favorável com referência à formulação do modelo de gestão intersetorial, com ênfase em ampla participação, não é unânime. Nesse sentido, um dos principais críticos ao modelo participativo criado para o projeto é o Entrevistado 5:

Nós estamos falando de territórios vulnerabilizados tanto social como ambientalmente. Vulnerabilidade civil onde você não tem liberdade de ir e vir, você é ameaçado o tempo todo, quer seja pelo tráfico, quer seja pelos agentes oficiais de segurança. Podemos contextualizar ou categorizar, como um território de exceção, mesmo dentro do Estado Democrático de Direito, no qual as pessoas não possuem a liberdade de se manifestar, de se organizar, de se expressar. É impossível superar o crime, o capital e o poder público, quando eles se juntam. Como é que nós queremos que essa população participe? Que morador vai para o confronto? A formação política e ideológica é a da subordinação para um modelo de poder pautado pela prática do terror. (Entrevistado 5).

Conforme o relato do Entrevistado 5, o formato representativo dos diversos grupos dentro do conselho apenas replica a lógica de não participação, uma vez que esses mesmos grupos, inabilitados a se manifestar por suas condições vulneráveis, não foram estimulados pelo poder público a exercitar sua autonomia previamente. Nessas circunstâncias, sua capacidade de debater e expor demandas tende a ser subjugada pelos interesses da gestão, transformando o CGI, como ele próprio diz, em um instrumento "chapa branca".

Não obstante, o conteúdo dos demais depoimentos aponta para a existência de outros problemas. Alguns entrevistados destacam a própria estrutura da administração pública, em todos os níveis, como um importante fator limitante para a construção sólida de uma base intersetorial sustentável: 
Qual era a limitação de qualquer intersetorialidade? Era a diversidade de comando. A lógica de governo é uma lógica setorial, então tem um que mexe no transporte, tem outro que mexe na educação, outro que mexe em limpeza urbana e aí cada um comanda uma coisa. (Entrevistado 1).

Em outras palavras, significa dizer que, além de ter que superar uma lógica predominantemente fragmentada e setorializada quanto à concepção, a consolidação da abordagem intersetorial ainda precisa sobrepor-se às hierarquias e compartimentalizações que se encontram cristalizadas, primeiro, na ordem constitucionalmente estabelecida que divide reponsabilidades entre união, estado e município e, segundo, nas clausuras contratuais cuja única orientação é a estrita observância da legislação vigente.

Na esteira desse processo, há também a questão habitacional associada às obras do Programa de Aceleração do Crescimento (PAC). Entendida pelas instâncias governamentais envolvidas como carro-chefe de um conjunto de políticas capazes de reconfigurar, entre outros pontos, a paisagem urbana do território de Manguinhos, o PAC previa, entre suas ações, a desapropriação de casas, sua posterior derrubada e a remoção de seus moradores. Tal estratégia foi, não poucas vezes, interpretada como inadequada pela população local, gerando diversas manifestações de descontentamento.

Você tem também o PAC planejando remoções através da prefeitura. E a prefeitura também tem a saúde ali dentro com uma atuação de profissionais, equipes do Programa Saúde da Família que quando vai procurar o seu paciente, ué, cadê? Saiu. Para onde foi meu cadastrado? Ninguém sabe o que foi feito da pessoa, nem para onde vai". (Entrevistado 6).

Nota-se, ainda, uma nítida heterogeneidade, mesmo no grau tênue de articulação que alegadamente ainda pode existir entre os setores. A maior parte dos entrevistados apontam para diálogos mais ou menos permanentes entre Saúde, Educação e Assistência Social. Em oposição, conversar com a Segurança Pública parece praticamente impossível:

A gente teve um bom diálogo com a educação, ação social também, a gente conseguiu que eles viessem aqui pelo menos uma vez por semana escutar a população. Essas áreas tiveram um pouco mais de integração. Com a segurança foi muito assim, informativo, não tem negociação, não tem integração e o PAC, também, era muito mais o próprio estado sozinho. (Entrevistado 2).

Dessa forma, talvez seja possível escrever, de forma sintetizada, que a intersetorialidade ainda é algo clivado por diversas fragilidades. Entre elas, certamente, pode-se destacar a controversa questão da participação política dentro do território; a forte resistência provocada pela lógica jurídico-administrativa, naturalmente segmentada e hierarquizada; as ações independentes do PAC, sobretudo com relação às questões habitacionais e a nítida inexistência de diálogo com setores importantes, principalmente a segurança pública. A afirmação de que a intersetorialidade propriamente dita nunca existiu plenamente no território de Manguinhos é assegurada categoricamente pelo Entrevistado 1:

Intersetorialidade na acepção completa do termo nunca houve. Isso teria que se dar através de arranjos, parcerias com outros setores. Mas isso esbarra, e isso você vê tranquilamente, na segmentação da autoridade municipal, tem lá as secretarias que caminham juntas até certo ponto, depois não caminham mais. (Entrevistado 1).

Escrevendo de outra forma, insiste-se na ideia de que a abordagem intersetorial, ao partir da saúde como temática ampla, não encontra eco suficiente nos outros setores para consolidar-se, além de não conseguir sobreviver às peculiaridades da administração pública em todos os níveis e instâncias. 
No contexto do Projeto Teias-Escola Manguinhos, o conceito de intersetorialidade viu-se, assim, reduzido tão somente a mais uma palavra. Sobre isso, acrescenta-se o comentário do Entrevistado 7, quando se refere à intersetorialidade como "palavra mágica" e "quimera", além de ressaltar que manipulação dos conceitos presta-se tão somente a "uma disputa acadêmica em que nem sempre o que está em primeiro plano é a necessidade do usuário".

Na perspectiva do Entrevistado 4, há um equívoco epistemológico quando se atribui à saúde essa missão integradora, sendo mais adequado entender a intersetorialidade como algo inerente ao campo sanitário, que requer a contribuição de outros setores sem situar-se acima deles. Se por um lado essa compreensão reduz expectativas e desfaz o nó abstrato, por outro, exime-se de propor outra abordagem de formulação e mantém o insulamento como obstáculo insuperável:

Do ponto de vista operacional não adianta que eu não vou praticar intersetorialidade sob domínio gerencial e político pleno da saúde no território de Manguinhos. Desse ponto de vista eu diria que isso é uma ilusão, isso é uma debilidade conceitual analítica e por aí vai. Me importa trabalhar com saúde escola? Me importa. Agora, isso não tem nada a ver com política educacional. Me importa trabalhar com a questão da violência na região? Me importa. Agora, eu não vou dirigir a UPP. (Entrevistado 4).

Nesse sentido, os dados apresentados e analisados sintetizam algumas articulações. O desequilíbrio de forças políticas aponta para uma alta suscetibilidade a desentendimentos administrativos e burocráticos. A resistência provocada pela lógica jurídico-administrativa, segmentada e hierarquizada, indica que os setores estão dispostos segundo um nexo vertical e estático. Intervenções independentes ampliam a possibilidade de sobreposição de ações e, por fim, a ausência de diálogo entre setores importantes gera conflitos entre as esferas governamentais.

Assim, entende-se ser coerente classificar o Projeto Teias-Escola Manguinhos como uma política pública pertencente exclusivamente ao campo multissetorial, que avança ainda lentamente na direção de outras abordagens. É o que procura deixar mais claro a figura 2:

Figura 2. Abordagem não setorial de formulação do Projeto Teias-Escola Manguinhos

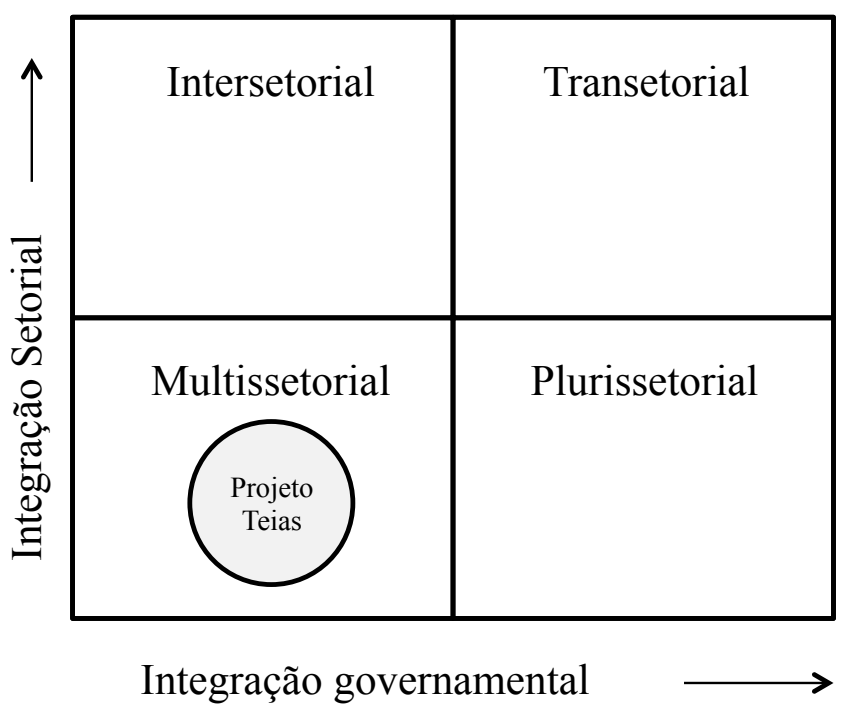

Nota: Elaboração própria 


\section{Considerações finais}

O objetivo deste artigo foi apresentar contribuições para o importante e instigante debate acerca da intersetorialidade, expondo lacunas que a situasse dentro de um possível novo referencial teórico-empírico, partindo da experiência prática do Projeto TeiasEscola Manguinhos.

No campo teórico, foi apresentado um breve ensaio com o objetivo de caracterizar abordagens não setoriais que pudessem lançar novas luzes para uma melhor compreensão dos graus de integração de setores e governos, no âmbito da formulação de políticas públicas. A discussão contou com o importante auxílio de autores consagrados, como o francês Edgar Morin e o brasileiro Naomar Almeida-Filho. Como resultado, emergiram os conceitos de multissetorialidade, plurissetorialidade, intersetorialidade e transetorialidade.

O debate desenhou-se de forma bastante complexa. Os dados empíricos coletados, não raramente, direcionaram a pesquisa para temas de grande complexidade, como participação popular, insulamento estrutural da administração pública e integração extremamente frágil da saúde com outros setores.

A conclusão a que se chega é que a intersetorialidade, de fato, nunca existiu em Manguinhos. Até então, trata-se apenas de uma intenção restrita exclusivamente ao campo teórico. Os dados empíricos, sobretudo os obtidos a partir das fontes orais, são generosos em identificar os principais problemas. Sua sistematização foi capaz de classificar o Projeto Teias como uma inciativa que compõe, na verdade, um quadro multissetorialista desarticulado. Essas evidências auxiliam o avanço no debate a partir do momento que desconstroem o dilema da intersetorialidade, simplesmente afirmando sua inexistência. Recuando-se para esse ponto, é possível enxergar com mais clareza quais rumos podem ser tomados no sentido de elaborar uma matriz analítica que possa ser extravasada para um campo pleno de políticas. Trata-se de alargar um marco conceitual.

Esse marco conceitual ampliado, todavia, é aqui apresentado de forma a deixar o debate ainda em aberto. Como última reflexão, cabe direcionar um olhar crítico para o território de Manguinhos e perguntar se todos esses esforços de formulação têm realmente contribuído para a melhoria da vida dos cidadãos que ali se configuram como extremamente dependentes do SUS e que, em última análise, são a razão de ser das políticas públicas, tão exaustivamente discutidas.

'Somos todos aprendizes' é o mantra entoado em uníssono por todos os atores envolvidos na formulação do Projeto TeiasEscola Manguinhos. Se de fato é assim, a pergunta que fica é: o que realmente foi aprendido até agora? 


\section{Referências}

AKERMAN, M. et al. Intersetorialidade? IntersetorialidadeS! Ciência \&t Saúde Coletiva, Rio de Janeiro, v. 19, n. 11, p. 4291-4300, 2014.

ALMEIDA FILHO, N. Transdisciplinaridade e saúde coletiva. Ciência \&t Saúde Coletiva, Rio de Janeiro, v. 11, n. 2, p. 1-18, 1997.

Intersetorialidade, transdisciplinaridade e saúde coletiva: atualizando um debate em aberto. Revista de Administração Pública, Rio de Janeiro, v. 34, n. 6, p. 11-34, 2000.

ANDRADE, L. O. M. A Saúde e o Dilema da Intersetorialidade. São Paulo: Hucitec, 2006.

ANDRADE, L. O. M.; BEZERRA, R. C. R.; BARRETO, I. C. H. C. O Programa de Saúde da Família como estratégia de atenção básica à saúde nos municípios brasileiros. Revista de Administração Pública, Rio de Janeiro, v. 39, n. 2, p. 328-348, 2005.

BARDIN, L. Análise de Conteúdo. Lisboa: Edições 70, 1977.

BODSTEIN, R. Avaliação de um projeto de desenvolvimento local integrado de promoção da saúde no Rio de Janeiro, Brasil. In: HARTZ, Z.; POTVIN, L.; BODSTEIN, R. Avaliação em Promoção da Saúde. Brasília, DF: CONASS, 2014.

CONFERÊNCIA NACIONAL DE SAÚDE, 12., 2004. Brasília, DF: Ministério da Saúde, 2004. Disponível em: <http://conselho.saude.gov.br/biblioteca/Relatorios/ relatorio_12.pdf >. Acesso em: 18 jun. 2015.

ENGSTROM, E.; FONSECA, Z.; LEIMANN, B. A experiência do território Escola Manguinhos na Atenção Primária de Saúde. Rio de Janeiro: Editora Fiocruz, 2012.

FERNANDES, T. M.; COSTA, R. G. R. História de pessoas e lugares: memórias das Comunidades de Manguinhos. Rio de Janeiro: Fiocruz, 2009.
GERSCHMAN, S. Políticas públicas articuladas e intersetoriais: a política de saúde em questão. In: OLIVEIRA, F. B. (Org.). Política de Gestão Pública Integrada. Rio de Janeiro: FGV, 2008.

JUNQUEIRA, L. A. P. Intersetorialidade, transetorialidade e redes sociais na saúde. Revista de Administração Pública, Rio de Janeiro, v. 34, n. 6, p. 35-45, 2000.

MARQUES, E. Estados e redes sociais: permeabilidade e coesão nas políticas urbanas no Rio de Janeiro. Rio de Janeiro: Revan, 2000.

MORIN, E. Ciência com Consciência. Rio de Janeiro: Bertrand Brasil, 1996.

NORONHA, J. C.; MACHADO, C. V.; LIMA, L. D. O Sistema Único de Saúde - SUS. In: GIOVANELLA, L. et al. (Org.). Políticas e Sistema de Saúde no Brasil. Rio de Janeiro: Fiocruz, p. 435-472, 2011.

PAIM, J. S. O que éo SUS? Rio de Janeiro: Fiocruz, 2012.

SANTOS, M. S. Integração e diferença em encontros disciplinares. Revista Brasileira de Ciências Sociais, São Paulo, v. 22, n. 65, p. 51-60. 2007.

SHANKARDASS, K. et al. A scoping review of intersectoral action for health equity involving governments. International Journal Public Health, Basileia, v. 57, n. 1, p. 25-33, 2012.

TEIXEIRA, C. F.; PAIM, J. Planejamento e programação de ações intersetoriais para a promoção da saúde e da qualidade de vida. Revista de Administração Pública. Rio de Janeiro, v. 34, n. 6, p. 63-80, 2000.

VERGARA, S. C. Métodos de pesquisa em administração. São Paulo: Atlas, 2012.

Recebido para publicação em abril de 2015

Versão final em junho de 2015

Conflito de interesse: inexistente

Suporte financeiro: não houve 